\title{
Distribution of small plastic fragments floating in the western Pacific Ocean from 2000 to 2001
}

\author{
Keiichi Uchida $^{1} \cdot$ Ryuichi Hagita $^{1} \cdot$ Toshifumi Hayashi $^{1} \cdot$ Tadashi Tokai $^{1}$ (]
}

Received: 21 May 2016 / Accepted: 14 September 2016 / Published online: 7 October 2016

(C) The Author(s) 2016. This article is published with open access at Springerlink.com

\begin{abstract}
Sampling was conducted at 31 sites in the western Pacific Ocean from 2000 to 2001 with the aim of collecting plastic fragments with a neuston net (mesh size $1.00 \mathrm{~mm} \times 1.64 \mathrm{~mm}$ ). Small plastic fragments including microplastics (small fragments in the size range of 1.1$41.8 \mathrm{~mm}$ ) were collected at multiple survey sites. Waters with high densities of small fragments were observed between $20^{\circ} \mathrm{N}$ and $30^{\circ} \mathrm{N}$ to the south of Japan and between $20 \mathrm{~S}$ and $30 \mathrm{~S}$ to the northeast of New Zealand (maxima of $6.63 \times 10^{2}$ and $2.03 \times 10^{2}$ pieces/ha, respectively). These waters are located to the west of the Ekman convergence zones related to trade winds in the subtropical gyres of the North and South Pacific Oceans. Nearly no small plastics were observed in the tropical circulation of the western Pacific Ocean.
\end{abstract}

Keywords Microplastics $\cdot$ Macroplastics $\cdot$ Subtropical gyre $\cdot$ Tropical circulation $\cdot$ Neuston net

\section{Introduction}

Small plastic fragments including plastic resin pellets that drift in the ocean have attracted attention since the 1970s due to their ability to adsorb and transport persistent organic pollutants [1,2]. Previous surveys conducted in Tokyo Bay and Sagami Bay suggested that the plastic resin pellets found in the ocean originated from the land [3]. Microplastics, which are derived from mismanaged

Tadashi Tokai

tokai@kaiyodai.ac.jp

1 Tokyo University of Marine Science and Technology, Konan, Minato, Tokyo 108-8477, Japan plastic wastes discharged into the ocean and are degraded into small fragments by exposure to ultraviolet radiation and mechanical erosion, have also attracted considerable attention [4]. The amount of these small plastic fragments is particularly high in the East Asian seas, including those around Japan [5]. The environmental risk of these small plastic fragments arises partly from their ingestion by marine organisms; moreover, recent studies have found ingested plastic fragments in a variety of marine organisms [6-8]. Although previous microplastic surveys have been conducted in the five gyres and marginal seas, there have been insufficient surveys in the tropical waters of the Pacific Ocean [5, 8-10]. In addition, microplastic, which is now regarded as an oceanic pollutant, has not been observed operationally; therefore, the archived dataset of plastic fragments in the world's oceans remains quite poor. Mismanaged plastic wastes discharged into the ocean are likely to increase rapidly over the next decade, especially from East and Southeast Asian countries [11]. The abundance of ocean-borne microplastics in the past provides us with important information to elucidate to what extent small plastic fragments have increased in the oceans in the past and to what extent these fragments will increase in the future.

Therefore, we present the abundance of small plastic fragments collected using a neuston net in the pelagic zone of the western Pacific from 2000 to 2001 aboard a training vessel belonging to the Tokyo University of Marine Science and Technology (previously, the Tokyo University of Fisheries). The survey areas (Fig. 1) covered a broad area in the western Pacific; therefore, the data will be useful for comparisons with microplastic abundances observed at nearby locations now and in the future. 


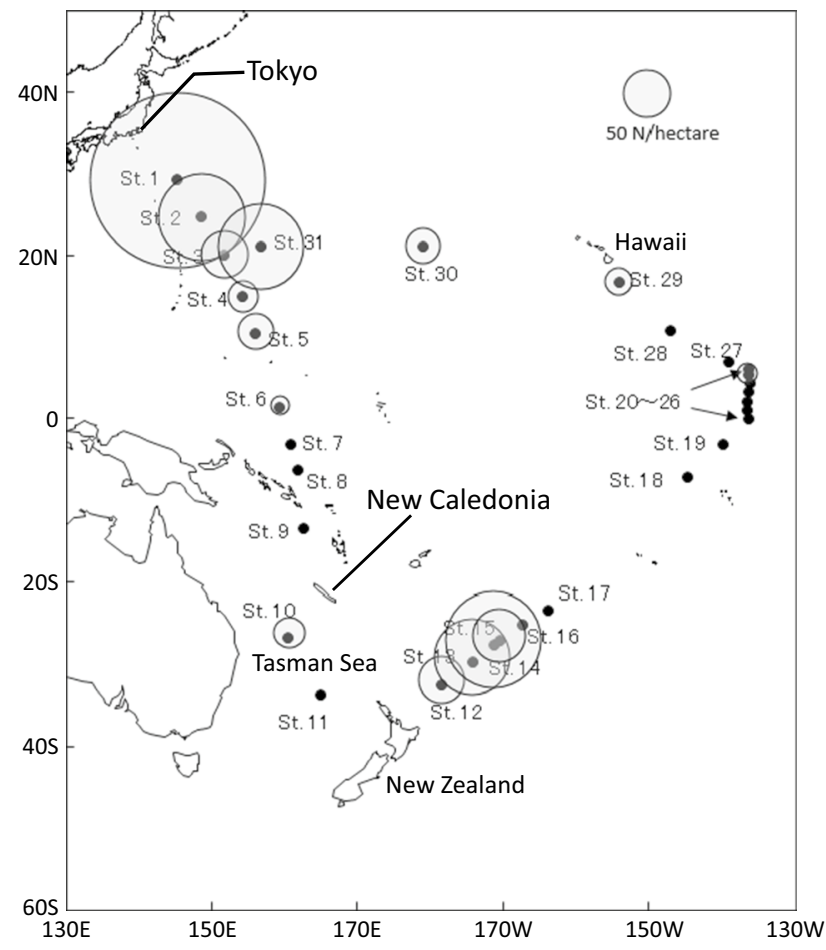

Fig. 1 Sampling locations and distribution density (number of fragments per unit area [pieces/ha, where ha $=10^{4} \mathrm{~m}^{2}$ ]) of small floating plastic fragments at each station (St.)

\section{Materials and methods}

The sampling was performed outside the exclusive economic zones of the surrounding countries during the period from October 2000 to March 2001 by the training vessel, Umitaka-maru IV, belonging to the Tokyo University of Marine Science and Technology. Because the primary aim of the survey was to collect small plastic fragments with sizes of a few millimeters including plastic resin pellets, which are regarded as one of the principle plastic polluters, a neuston net with a mouth of $700 \mathrm{~mm} \times 700 \mathrm{~mm}$ and a mesh size of $1.00 \mathrm{~mm} \times 1.64 \mathrm{~mm}$ was used for the surveys. The buoyancy of the net was adjusted such that the upper half of the net mouth was exposed above the sea surface while being towed approximately $1 \mathrm{~m}$ from the port side hull of the ship. The ship speed during towing was maintained at approximately 2-3 knots during each 10-min tow. The start and finish locations of the transects were determined on the basis of the latitude and longitude coordinates measured using a global positioning system (GPS). Sampling was conducted every 2 days unless towing was difficult due to stormy weather conditions.

In the laboratory onboard the ship, the small plastic fragments were immediately spotted with the naked eye and separated from natural materials, including zooplankton, based on shapes and colors in a manner similar to Ogi and
Fukumoto [1]. The plastic fragments were then counted and photographed using a digital camera. The material composition of the collected plastic fragments was not determined in this study. After the voyage, the length of the longest axis of each fragment was measured from the digital photographs. The fragments were classified according to their shapes, such as granular, sheet-like, string-like, based on the photographs. For this study, the volume of seawater passing through the net could not be calculated because a flow meter was not installed at the mouth of the net. Therefore, the filtered area was estimated on the basis of the width of the net mouth and the towing distance, which was determined using the GPS data. In the procedure used to measure the small plastic fragments, the "distribution density" of the fragments was defined as the number of fragments per unit area (pieces/ha, where ha $=10^{4} \mathrm{~m}^{2}$ ).

\section{Results}

In total, sampling was conducted at 31 stations: nine stations between Tokyo and New Caledonia (stations 1-9), two stations between New Caledonia and New Zealand (stations 10 and 11), six stations between New Zealand and Tahiti (stations 12-17), 12 stations between Tahiti and Hawaii (stations 18-29), and two stations between Hawaii and Tokyo (stations 30 and 31). The locations of stations 20-26 were crowded because they were sampled in conjunction with operations with tuna longline fisheries. Small plastic fragments were collected at 15 of 31 stations (see Fig. 1; Table 1 for the distribution density at each station). Figure 2 shows photographs of all the fragments collected at each station. Every plastic particle appeared to be a fragment or plastic fiber derived from the breakdown of larger plastic products. No virgin plastic pellets, such as discshaped or cylindrical plastic resin pellets, were found in the collected plastic fragments (Fig. 2). Granular fragments were the most commonly collected, comprising $67 \%$ of the total (Fig. 2; Table 1). The greatest variety of plastic fragment shapes was found at station 1 .

The highest distribution density was also found at station 1 , closest to Japan $\left(6.63 \times 10^{2}\right.$ pieces/ha $)$. At station 1 , a roll of plastic tape was found together with plastic fragments, as shown in Fig. 2 (the red object at station 1); however, these fragments were excluded from the analysis because they were not categorized as found "small plastic fragments," the objective of the study. The distribution density decreased moving southward from the mid-latitudes in the Northern Hemisphere to the equator, and small plastic fragments were not found at stations 7-9 in the Southern Hemisphere beyond the equator. However, in the Tasman Sea, plastic fragments, at a density of $2.24 \times 10^{2}$ pieces/ha, were again collected at station 10 . Furthermore, between 
Table 1 Sampling locations, number of small floating plastic fragments collected at each station (St.) according to item type, and estimated distribution density [number of fragments per unit area (pieces/ha, where ha $=10^{4} \mathrm{~m}^{2}$ )]

\begin{tabular}{|c|c|c|c|c|c|c|c|c|c|}
\hline \multirow[t]{2}{*}{ St. no. } & \multirow[t]{2}{*}{ Date } & \multicolumn{2}{|c|}{ Sampling location } & \multicolumn{5}{|c|}{ Item shape } & \multirow{2}{*}{$\begin{array}{l}\text { Density } \\
\text { Pieces/ha }\end{array}$} \\
\hline & & Latitude & Longitude & Granular & String & Sheet & Others & Sub-total & \\
\hline 1 & 13 December 2000 & $29-10.45 \mathrm{~N}$ & $145-20.94 \mathrm{E}$ & 18 & 2 & 9 & 13 & 42 & $6.63 \times 10^{2}$ \\
\hline 2 & 14 December 2000 & $24-32.99 \mathrm{~N}$ & $148-36.46 \mathrm{E}$ & 9 & 0 & 1 & 2 & 12 & $1.68 \times 10^{2}$ \\
\hline 3 & 15 December 2000 & $20-00.21 \mathrm{~N}$ & $151-50.27 \mathrm{E}$ & 6 & 0 & 0 & 0 & 6 & $5.1 \times 10$ \\
\hline 4 & 16 December 2000 & $14-47.45 \mathrm{~N}$ & $154-16.25 \mathrm{E}$ & 2 & 1 & 0 & 0 & 3 & $2.1 \times 10$ \\
\hline 5 & 17 December 2000 & $10-25.08 \mathrm{~N}$ & $156-01.27 \mathrm{E}$ & 2 & 0 & 1 & 0 & 3 & $2.9 \times 10$ \\
\hline 6 & 19 December 2000 & $01-15.80 \mathrm{~N}$ & $159-24.29 \mathrm{E}$ & 0 & 1 & 0 & 0 & 1 & $0.8 \times 10$ \\
\hline 7 & 20 December 2000 & 03-18.49S & $160-52.99 \mathrm{E}$ & 0 & 0 & 0 & 0 & 0 & 0 \\
\hline 8 & 21 December 2000 & $06-19.51 \mathrm{~S}$ & $161-52.03 \mathrm{E}$ & 0 & 0 & 0 & 0 & 0 & 0 \\
\hline 9 & 22 December 2000 & $13-32.65 \mathrm{~S}$ & $162-41.69 \mathrm{E}$ & 0 & 0 & 0 & 0 & 0 & 0 \\
\hline 10 & 31 December 2000 & $26-49.37 \mathrm{~S}$ & $160-39.08 \mathrm{E}$ & 1 & 0 & 0 & 1 & 2 & $2.2 \times 10$ \\
\hline 11 & 10 January 2001 & $33-49.37 \mathrm{~S}$ & $165-02.66 \mathrm{E}$ & 0 & 0 & 0 & 0 & 0 & 0 \\
\hline 12 & 18 January 2001 & $32-35.68 \mathrm{~S}$ & $178-18.04 \mathrm{E}$ & 1 & 2 & 1 & 0 & 4 & $5.0 \times 10$ \\
\hline 13 & 19 January 2001 & $29-46.27 \mathrm{~S}$ & $174-06.58 \mathrm{E}$ & 7 & 2 & 0 & 0 & 9 & $1.26 \times 10^{2}$ \\
\hline 14 & 21 January 2001 & $27-36.84 S$ & 171-07.67E & 17 & 0 & 0 & 0 & 17 & $2.03 \times 10^{2}$ \\
\hline 15 & 21 January 2001 & $27-07.61 \mathrm{~S}$ & $170-20.95 \mathrm{E}$ & 5 & 0 & 0 & 0 & 5 & $6.3 \times 10$ \\
\hline 16 & 22 January 2001 & $25-12.71 \mathrm{~S}$ & $167-12.71 \mathrm{E}$ & 0 & 0 & 0 & 0 & 0 & 0 \\
\hline 17 & 23 January 2001 & $23-33.74 \mathrm{~S}$ & $163-36.04 \mathrm{E}$ & 0 & 0 & 0 & 0 & 0 & 0 \\
\hline 18 & 3 February 2001 & $07-19.52 \mathrm{~S}$ & $144-49.23 \mathrm{E}$ & 0 & 0 & 0 & 0 & 0 & 0 \\
\hline 19 & 4 February 2001 & 03-14.46S & $139-55.90 \mathrm{E}$ & 0 & 0 & 0 & 0 & 0 & 0 \\
\hline 20 & 6 February 2001 & $00-08.79 \mathrm{~N}$ & $136-21.67 \mathrm{E}$ & 0 & 0 & 0 & 0 & 0 & 0 \\
\hline 21 & 7 February 2001 & $00-58.33 \mathrm{~N}$ & $136-35.49 \mathrm{E}$ & 0 & 0 & 0 & 0 & 0 & 0 \\
\hline 22 & 8 February 2001 & $02-03.49 \mathrm{~N}$ & $136-31.10 \mathrm{E}$ & 0 & 0 & 0 & 0 & 0 & 0 \\
\hline 23 & 9 February 2001 & $03-12.52 \mathrm{~N}$ & $136-19.62 \mathrm{E}$ & 0 & 0 & 0 & 0 & 0 & 0 \\
\hline 24 & 10 February 2001 & $04-18.03 \mathrm{~N}$ & $136-12.79 \mathrm{E}$ & 0 & 0 & 0 & 0 & 0 & 0 \\
\hline 25 & 11 February 2001 & $05-14.29 \mathrm{~N}$ & $136-16.42 \mathrm{E}$ & 0 & 0 & 0 & 1 & 1 & $1.0 \times 10$ \\
\hline 26 & 12 February 2001 & $05-59.37 \mathrm{~N}$ & $136-16.37 \mathrm{E}$ & 0 & 0 & 0 & 0 & 0 & 0 \\
\hline 27 & 13 February 2001 & $06-48.33 \mathrm{~N}$ & 139-04.23E & 0 & 0 & 0 & 0 & 0 & 0 \\
\hline 28 & 16 February 2001 & $10-45.68 \mathrm{~N}$ & $146-59.67 \mathrm{E}$ & 0 & 0 & 0 & 0 & 0 & 0 \\
\hline 29 & 18 February 2001 & $16-37.30 \mathrm{~N}$ & $153-51.34 \mathrm{E}$ & 2 & 0 & 0 & 0 & 2 & $1.8 \times 10$ \\
\hline 30 & 3 March 2001 & $20-59.74 \mathrm{~N}$ & 179-09.52E & 2 & 0 & 0 & 1 & 3 & $2.9 \times 10$ \\
\hline \multirow[t]{2}{*}{31} & 6 March 2001 & $21-00.78 \mathrm{~N}$ & $156-50.58 \mathrm{E}$ & 13 & 2 & 0 & 1 & 16 & $1.64 \times 10^{2}$ \\
\hline & & & Total & 85 & 10 & 12 & 19 & 126 & \\
\hline
\end{tabular}

New Zealand and Tahiti, a distribution density of $5.0 \times 10^{2}$ pieces/ha was observed at station 12 northeast of New Zealand. The highest density of small plastics observed in the Southern Hemisphere was $2.03 \times 10^{2}$ pieces/ha, which was recorded at station 14 further northeast of New Zealand. The density was relatively low $(6.3 \times 10$ pieces/ha $)$ at station 15. In addition, no small plastic fragments were collected to the north of station 16 in the Southern Hemisphere. At station 25 in the Northern Hemisphere between Tahiti and Hawaii, only burned fragments of a petrochemical material were collected (see Fig. 2). A density of $1.8 \times 10$ pieces/ha was recorded at station 29 to the south of Hawaii, and the density tended to increase from Hawaii (station 30, density $2.9 \times 10$ pieces/ha) toward Japan (station 31 , density $1.64 \times 10^{2}$ pieces/ha). As mentioned previosly, $67 \%$ of the fragments collected in this study had a granular shape, and a relatively large amount of granularshaped fragments was observed over the entire study area (see Table 1).

The sizes of the small plastic fragments were determined by their length along their longest axis, and their size range was from 1.1 to $41.8 \mathrm{~mm}$ with an average of $5.7 \mathrm{~mm}$ and a median of $3.6 \mathrm{~mm}$ (Fig. 3). Approximately $70 \%$ of the fragments were categorized as "microplastics," defined as plastic fragments $<5 \mathrm{~mm}$ [12]. No fragments $<1 \mathrm{~mm}$ were collected due to the net mesh size of $1.00 \mathrm{~mm} \times 1.64 \mathrm{~mm}$ 

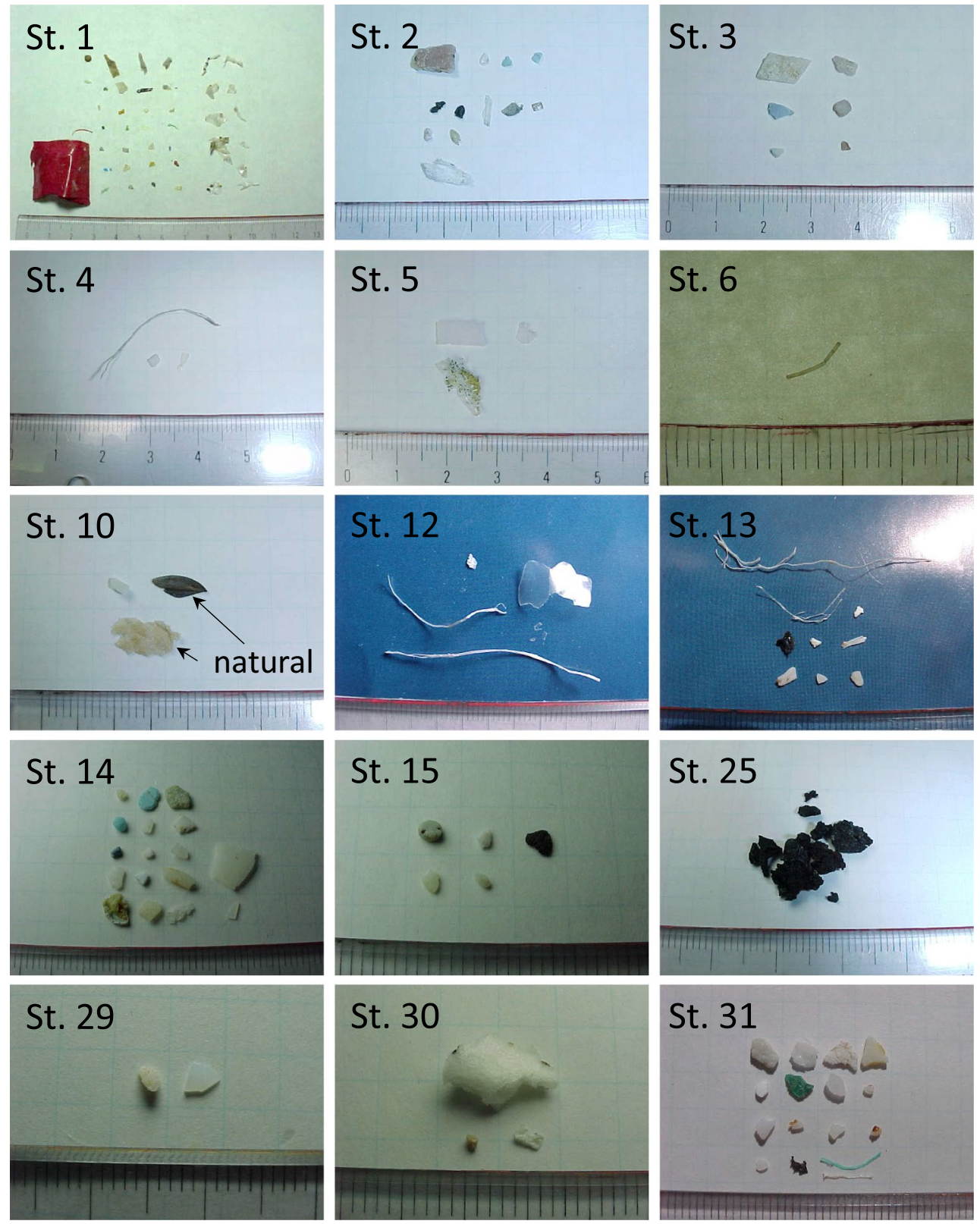

Fig. 2 Photographs of the small floating plastic fragments collected at each station

(Fig. 3). The mean sizes of the fragments collected in the Northern and Southern Hemispheres were not statistically significantly different $(t=0.24, p>0.05)$.

\section{Discussion}

In this survey, high densities of small plastic fragments ( $>50$ pieces/ha) were observed in the waters from $20^{\circ} 0^{\prime} \mathrm{N}$ to $29^{\circ} 10^{\prime} \mathrm{N}$ to the south of Japan and from $27^{\circ} 8^{\prime} \mathrm{S}$ to $32^{\circ} 36^{\prime} \mathrm{S}$ to the northeast of New Zealand. There are surface convergence regions in the subtropical gyres in the North
Pacific, South Pacific, North Atlantic, South Atlantic, and Indian oceans [8]. The convergence of floating marine debris in these waters occurs due to a similar mechanism: floating marine debris converges toward a mid-latitude belt by the Ekman flows and then moves further eastward due to geostrophic currents to form a high-density region $[13,14]$. The high densities of plastic fragments observed in both the North and South Pacific Oceans were located in the western areas of the subtropical convergence regions in the midlatitudes [8]. However, floating marine debris in equatorial waters is likely to be continually transported westward in the absence of a convergence zone until the debris reaches 


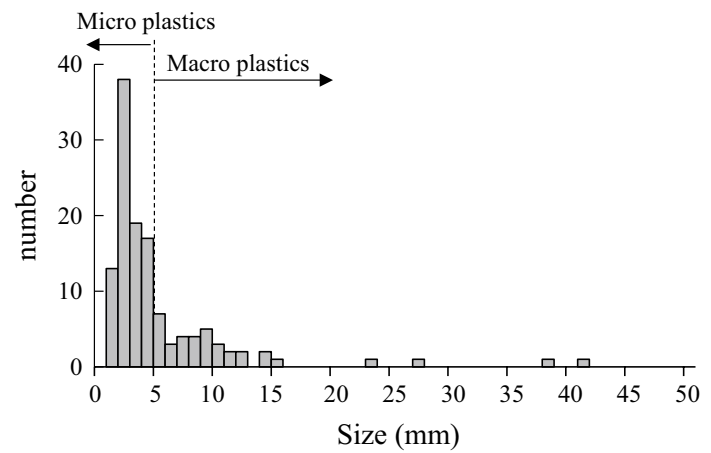

Fig. 3 Frequency distribution of the longest-axis length of the plastic fragments collected by visual identification. Plastic fragments with a long axis $<5 \mathrm{~mm}$ accounted for $70 \%$ of the collected samples

a zone east of the Philippines and the Indonesian archipelago due to the equatorial currents (see Kubota et al. [14] for the argument for the Northern Hemisphere). In fact, except for the burned fragments collected at station 25 , practically no small plastic fragments were collected over the tropical waters in the presented survey (stations 7-9 and 18-28). The burned petrochemical fragments collected at station 25 might have been released from one of the tuna longline fishing vessels operating in the vicinity. Jembeck et al. [11] suggested that some countries in East and Southeast Asia discharge a large amount of mismanaged plastic wastes into the ocean and Isobe et al. [5] demonstrated that the waters around Japan downstream of these countries were a hot spot for pelagic microplastic due to the Kuroshio Current [5]. This suggests that microplastics may flow into the North Pacific from this hot spot.

The mode of the fragment size observed in this study was approximately $3 \mathrm{~mm}$. The abundance of the fragments decreased as they become smaller than the mode size, and no fragments with a size $\leq 1 \mathrm{~mm}$ were collected (Fig. 3). As mentioned above, this may have been caused in part by the relatively coarse mesh size of the neuston net $(1.00 \mathrm{~mm} \times 1.64 \mathrm{~mm})$. In addition, the use of a stereomicroscope rather than the naked eye to identify the small plastic fragments might have increased their numbers, especially in size ranges $<3 \mathrm{~mm}$. Neuston nets with a mesh size of $0.333 \mathrm{~mm}$ have been used for microplastic surveys in recent years $[5,15]$. In those studies (e.g., Isobe et al. $[5,16])$, the mode in the longest axis length was in the vicinity of $1 \mathrm{~mm}$, and a large amount of microplastics $<1 \mathrm{~mm}$ was also collected. According to Eriksen et al. [9], approximately $40 \%$ of the plastic fragments were $<1 \mathrm{~mm}$ in their survey conducted in the eastern South Pacific in 2011. Consequently, the distribution densities of microplastics in the presented study were potentially underestimated. Therefore, it is not possible to make an in-depth examination of microplastic behaviors here, such as their vertical distribution (e.g., Kukulka et al. [17]); this will be explored in a future study.

The presented study provides an overview of the distribution of small plastic fragments in the western Pacific Ocean from 2000 to 2001. However, future studies will need to employ neuston nets equipped with a flow meter, and with a finer mesh size, as seen in recent studies. Note that the distribution densities computed in the presented study might not be directly comparable to other microplastic data obtained under different wind/wave conditions. This is because the density of lightweight microplastics drifting in the surface layer rapidly decreases (increases) in the high (low) vertical mixing under stormy (calm) oceanic conditions. Vertically integrating the densities at depth yields the microplastic data for the entire water column; therefore, these values are required for comparisons with other microplastic data collected under other oceanic conditions irrespective of vertical mixing. Such a "vertical correction" should be performed on the fragment abundance obtained in the presented study using archived wave/wind data. Recently, a survey of small plastic fragments in conjunction with the sequential monitoring of wind/waves was conducted by the training vessel Umitaka-maru along a track from the Antarctic Ocean to Tokyo during the period of February-March 2016. These surveys included sampling in the vicinity of stations $1-11$ of this study; therefore, we can demonstrate changes in the distribution densities, sizes, and shapes of small plastic fragments over the past 15 years.

Acknowledgments The authors sincerely thank the officers and crew of the training vessel Umitaka-maru for their assistance during the field surveys and two anonymous reviewers for their very helpful suggestions and constructive comments. This study was partly supported by the Environmental Research and Technology Development Fund (4-1502) of the Ministry of the Environment, Japan.

Open Access This article is distributed under the terms of the Creative Commons Attribution 4.0 International License (http://creativecommons.org/licenses/by/4.0/), which permits unrestricted use, distribution, and reproduction in any medium, provided you give appropriate credit to the original author(s) and the source, provide a link to the Creative Commons license, and indicate if changes were made.

\section{References}

1. Ogi H, Fukumoto Y (2000) A sorting method for small plastic debris floating on the sea surface and stranded on a sandy beach. Bull Fac Fish Hokkaido Univ 51:71-93

2. Mato Y, Isobe T, Takada H, Kanehiro H, Ohtake K, Kaminuma T (2001) Plastic resin pellets as a transport medium for toxic chemicals in the marine environment. Environ Sci Technol 35:318-324. doi:10.1021/es0010498

3. Kuriyama Y, Konishi K, Kaneihiro H, Otake C, Kaminuma T, Mato Y, Takada S, Kojima A (2002) Plastic pellets in the marine 
environment of Tokyo Bay and Sagami Bay. Nippon Suisann Gakkaishi 682:164-171. doi:10.2331/suisan.68.164

4. Thompson RC, Olsen Y, Mitchell RP, Davis A, Rowland SJ, John AWG, McGonigle D, Russell AE (2004) Lost at sea: where is all the plastic? Science 304:838. doi:10.1126/science.1094559

5. Isobe A, Uchida K, Tokai T, Iwasaki S (2015) East Asian seas: a hot spot of pelagic microplastics. Mar Poll Bull 101:618-623. doi:10.1016/j.marpolbul.2015.10.042

6. Wright SI, Thompson RC, Galloway TS (2013) The physical impacts of microplastics on marine organisms: a review. Environ Pollut 178:1-10. doi:10.1016/j.envpol.2013.02.031

7. Lisbeth VC, Colin RJ (2014) Microplastics in bivalves cultured for human consumption. Environ Pollut 193:65-70. doi:10.1016/j.envpol.2014.06.010

8. Lusher A (2015) Microplastics in the marine environment: distribution, interactions and effects. In: Bergmann M, Gutow L, Klages M (eds) Marine anthropogenic litter. Part III. Springer, Heidelberg, pp 245-307. doi: 10.1007/978-3-319-16510-3_10

9. Eriksen M, Lebreton LCM, Carson HS, Thiel M, Moore CJ, Borerro JC, Galgani F, Ryan PG, Reisser J (2014) Plastic pollution in the world's oceans: more than 5 trillion plastic pieces weighing over 250,000 tons afloat at sea. PLoS One 9:e111913. doi:10.1371/journal.pone.0111913

10. Erik VS, Chris W, Laurent L, Nikolai M, Britta DH, January AF, Marcus E, David S, Francois G, Kara LL (2015) A global inventory of small floating plastic debris. Environ Res Lett 10:124006. doi:10.1088/1748-9326/10/12/124006

11. Jambeck JR, Geyer R, Wilcox C, Siegler TR, Perryman M, Andrady A, Narayan R, Law KL (2015) Plastic waste inputs from land into the ocean. Science 347:768-771. doi:10.1126/ science. 1260352

12. Andrady L (2011) Microplastics in the marine environment. Mar Pollut Bull 62:1596-1605. doi:10.1016/j.marpolbul.2011.05.030

13. Kubota M (1994) A mechanism for the accumulation of floating marine debris North of Hawaii. J Phys Oceanogr 24:1059-1064. doi:10.1175/1520-0485(1994)024<1059:AMFTAO>2.0.CO;2

14. Kubota M, Takayama K, Namimoto D (2005) Pleading for the use of biodegradable polymers in favor of marine environments and to avoid an asbestos-like problem for the future. Appl Microbiol Biotechnol 67:469-476. doi:10.1007/s00253-004-1857-2

15. Hidalgo V, Gutow L, Thompson RC, Thiel M (2012) Microplastics in the marine environment: a review of the methods used for identification and quantification. Envir Sci Tech 46:3060-3075. doi:10.1021/es2031505

16. Isobe A, Kubo K, Tamura Y, Kato S, Nakashima E, Fujii N (2014) Selective transport of microplastics and mesoplastics by drifting in coastal waters. Mar Pollut Bull 89:324-330. doi:10.1016/j.marpolbul.2014.09.041

17. Kukulka T, Proskurowski G, Morét-Ferguson SE, Meyer DW, Law KL (2012) The effect of wind mixing on the vertical distribution of buoyant plastic debris. Geophys Res Lett 39:L07601. doi:10.1029/2012GL051116 